\title{
The Stability of Banking System Based on Network Structure: An Overview
}

\author{
Qianqian Gao ${ }^{1}$, Hong Fan ${ }^{1}$, Jiwei Shen ${ }^{2}$ \\ ${ }^{1}$ Glorious Sun School of Business and Management, Donghua University, Shanghai, China \\ ${ }^{2}$ Middle School of Zhoujia, Liaoning, China \\ Email: ^qianqiangaodhu@163.com,hongfan@dhu.edu.cn,2126204713@qq.com
}

How to cite this paper: Gao, Q.Q., Fan, H. and Shen, J.W. (2018) The Stability of Banking System Based on Network Structure: An Overview. Journal of Mathematical Finance, 8, 517-526. https://doi.org/10.4236/jmf.2018.83032

Received: May 23, 2018

Accepted: June 25, 2018

Published: June 28, 2018

Copyright (c) 2018 by authors and Scientific Research Publishing Inc. This work is licensed under the Creative Commons Attribution International License (CC BY 4.0).

http://creativecommons.org/licenses/by/4.0/

\section{c) (7) Open Access}

\begin{abstract}
The global financial crisis triggered by the US subprime mortgage crisis in 2008 has caused serious impact on the financial system around the world, which also aggravated the banking system. Since the banking industry is the core element of financial system, various scholars and relevant regulatory authorities have paid attention to the stability of the banking system. Unlike the traditional qualitative research, many scholars have adopted the method of computational finance based on the complex network theory to explore the banking system in recent years. Therefore, this paper has carried out a literature review of the stability of banking system under different network structures. It presents the analysis of model and results so as to have a clear understanding on the topic.
\end{abstract}

\section{Keywords}

Financial System, The Stability of Banking System, Network Structure

\section{Introduction}

The financial activities have been expanded and deepened on a global scale in the process of economic and financial globalization. As a result, the environment of modern financial system has become more and more complex and presents multiple complex forms. And, as the banking system tends to be complex, the complexity and extent of the financial crisis are also gradually increasing. From the Latin American debt crisis in the 1980s, the European monetary system crisis, the Mexican financial crisis, etc., to the recent US subprime mortgage crisis and the European sovereign debt crisis, the international financial crisis has caused countries around the world to suffer different degrees of damage, and the development of economic activities has been hampered, among which the 
banking industry has suffered heavy losses. When the banking system encounters external shocks, individual banks fail to resist due to their own limited conditions and hence default, and then, it will create domino effects (the risk caused by the default of one or several banks is spread within the banking system under the shock, resulting in the loss or collapse of the entire banking system, which is often referred to as "the domino effect") through the interbank linkages, which makes the banking system face greater risks. Therefore, maintaining the stability of the banking system is of great significance, and the turbulence in global financial markets brought by the financial crisis has made it a hot topic for scholars globally.

Due to the widespread application of the complex network theory in the financial field, many scholars use it to simplify the banking system, and banks and other financial institutions are usually used as nodes, and their interbank linkages are used as edges, and this connection between nodes and edges represents the financial network. The financial network is similar to the traditional network, which is mainly composed of nodes and edges. The difference is that, on one hand, the number of financial network nodes is usually a lot, thus often constituting a more complex network; on the other hand, each edge measures the balance of assets and liabilities between two connected nodes, and the edges are sometimes directional. Therefore, the banking system is a complex system composed of a large number of banks and their related links.

In the complex network theory, the network structure has different forms, including regular networks and complex networks. In a regular network, the connection between nodes has a fixed rule, and the number of neighbors of any node is the same. Complex networks are divided into random network, small-world network and scale-free network as well as core-edge network. In the random network, the connection between nodes is completely random and the degree of each node is very close, and also, there are relatively few nodes with very small and large degree. The small-world network is generated by adding randomness based on the regular network, and it has smaller average path length and larger aggregation coefficients. Moreover, the distribution of nodes' degree is exponential. In the scale-free network, the degree of a few nodes is very large (these nodes are connected to most nodes) and most nodes are very small (these nodes are only connected to a few nodes), and the degree of nodes obeys the power law distribution. In the core-edge network, core (periphery) banks are maximally (minimally) connected to each other. With the development of the complex network theory, various scholars have explored the stability of the banking system based on the perspective of network structure. Some scholars mainly use the relevant theory of complex network to construct the banking system network model, and explore the stability of the banking system under different network structures when it is shocked. In addition, some scholars have collected the actual data from the banking industry in their country, and verified the network structure of banking system by analyzing the degree distribution of 
actual banks. Furthermore, they could study the stability of the banking system based on the actual network structure empirically. Therefore, we review the existing relevant literatures theoretically and empirically in order to make other researchers have a clear understanding of the topic as summarized in Table 1. We review the theoretical and empirical research in Section 2 and Section 3 respectively, and Section 4 provides the conclusion.

\section{Theoretical Research}

By sorting out the existing relevant literatures, we found that the theoretical analysis of the banking system stability under different network structures mainly focuses on three aspects: the stability of banking system under the simple network structure (regular networks), the scale-free network or core-edge network and the comparative study of the stability of banking system with different network structures.

Allen and Gale [1] and Freixas et al. [2] pioneered research on the contagion effects of financial risk based on the assumption of a simple network structure, and they considered that the banking system with complete structure that had interbank linkages between any two banks was more stable than that of the incomplete structure. Babus [3] developed interbank deposits endogenously (liquidity shocks) based on Allen and Gale [1], the research showed that complete network could always provide the conditions for banks to choose the optimal connectivity degree, while incomplete network may not necessarily provide this condition. The studies of Freixas et al. [2], Thurner et al. [4] and Elsinger et al. [5] are relatively deeper. Freixas et al. [2] compared complete network structure

Table 1. Research overview of the stability of banking system from the perspective of network structure.

\begin{tabular}{|c|c|c|}
\hline & Research & Main researchers \\
\hline \multirow{3}{*}{$\begin{array}{l}\text { Theoretical } \\
\text { research }\end{array}$} & Regular networks & $\begin{array}{l}\text { Allen and Gale (2000), Freixas et al. (2000), } \\
\text { Thurner et al. (2003), Babus (2005), } \\
\text { Elsinger et al. (2006), Acemoglu et al. (2015) }\end{array}$ \\
\hline & $\begin{array}{l}\text { Scale-free network } \\
\text { or core-edge network }\end{array}$ & $\begin{array}{l}\text { Krause and Giansante (2012), } \\
\text { Teteryatnikova (2014), Sui et al. (2014), } \\
\text { Borgatti and Everett (2000), Lux (2015) }\end{array}$ \\
\hline & $\begin{array}{l}\text { Comparative study of } \\
\text { different network structures }\end{array}$ & $\begin{array}{c}\text { Lenzu and Tedeschi (2012), } \\
\text { Li et al. (2012), Bao and Sun (2014) }\end{array}$ \\
\hline \multirow[t]{2}{*}{$\begin{array}{l}\text { Empirical } \\
\text { research }\end{array}$} & $\begin{array}{l}\text { Network characteristics } \\
\text { of the banking system }\end{array}$ & $\begin{array}{l}\text { Boss et al. (2004), Inaoka et al. (2004), } \\
\text { Iori et al. (2008), Becher et al. (2008), Cont } \\
\text { et al. (2010), Martinez-Jaramillo et al. (2010), } \\
\text { Gabrieli (2011), Veld and Lelyveld (2014), } \\
\text { León and Berndsen (2014), Liu et al. (2014), } \\
\text { Bargigli et al. (2015), Sui and Wang (2015) }\end{array}$ \\
\hline & $\begin{array}{l}\text { The stability of banking system } \\
\text { with different network structures }\end{array}$ & $\begin{array}{l}\text { Degryse and Nguyen (2007), } \\
\text { Gao and Pan (2012) }\end{array}$ \\
\hline
\end{tabular}

Source: Papers download from Web of Knowledge and CKNI. 
with ring network structure (any node in the network is connected only to the other two nodes, and forms a ring), the study revealed that contagion of bank's default depend on the parameters set by the model. Thurner et al. [4] compared the default contagion in the interbank market under several regular network structures. While, Elsinger et al. [5] thought that simply distinguishing between complete and incomplete network structure could not accurately reveal the relationship between network structure and bank's stability. In addition, Acemoglu et al. [6] studied the relationship between the financial network structure and systemic risk based on the two basic regular networks (ring and complete financial network). It was found that financial contagion had a phase change characteristic: when the shock was less than a certain threshold, the affected financial institutions were less and the increase of interbank connection would enhance the financial stability; however, once it exceed the threshold, the interbank connection would cause the shocks to spread, thus made the financial system more vulnerable, which supported that the financial network were "robust yet fragile".

Some scholars studied the stability of the banking system with scale-free network or core-edge network. Among them, Krause and Giansante [7], Teteryatnikova [8] and Sui et al. [9] studied it under the scale-free network, Borgatti and Everett [10] and Lux [11] studied the core-edge network. Krause and Giansante [7] simulated interbank network with different scale-free parameters, their study suggested that the smaller the interbank scale-free parameter and the higher the degree of concentration, the smaller the possibility of contagion. Teteryatnikova [8] simulated the banking system under special shocks caused by operational risk or credit risk using two methods: heterodyne network and scale-free network. The research showed that as long as the highly connected banks were fully capitalized, the risk of systemic crisis and the scope of crisis in the banking system were both low, and the resilience of scale-free network to contagion increased with the level of tiering. Sui et al. [9] constructed a scale-free network to simulate the default contagion in the banking network system with different network parameters under random shock and two special shocks (bank default started from larger and smaller banks respectively). The study found that the higher the concentration of scale-free network, the more default banks caused by contagion; however, when the basic default banks were few, the higher the concentration of scale-free network, the less total assets of the default bank caused by contagion. At the same time, the possibility of small banks causing contagion was far lower than that of large banks, but when the default of small banks reached a certain scale, it could lead to large banks' contagious default. Borgatti and Everett [10] firstly proposed the core-periphery network models. They divided a network into subgroups of core and periphery members. Lux [11] studied the network structure of the banking system by constructing a dynamic model of interbank credit linkages in the interbank lending market. In the model, the bank was initially set up to randomly select potential trading partners and then formed a priority choice relationship according to a basic reinforcement learning algorithm, and because of the shock on bank deposits, banks must con- 
stantly adjust their assets and liabilities. The dynamic evolution of this system showed the formation of the banking system with core-edge network. Moreover, the study found that most of the largest banks played an intermediary role in transferring liquidity demands between many smaller banks, and that the asymmetry of bank's interests flows from edge to the monetary center could at least be neutralized at a certain level through the heterogeneous interest rate. In addition, Teteryatnikova [8] suggested that regulators should seek measures to promote interbank relationships to form a highly hierarchical system, and require more strict supervision for key banks. Also, when banks default and showed the signs of contagion, it's necessary to determine the rescue market scope based on the characteristics of the banking network.

Meanwhile, some scholars also conducted a comparative analysis of the stability of banking system under different network structures. Lenzu and Tedeschi [12] constructed a model of interbank lending formed by heterogeneous financial institutions. They studied the stability and systemic risk of the banking system with different network structures when the banking system was faced with equivalent but opposite sign of liquidity shocks. The research showed that when the banking system was heterogeneous, it was more stable with random network than that of the scale-free network. Li et al. [13] studied the bank's risk contagion effects in homogeneous and heterogeneous banking system with small-world network, random network and scale-free network when it was faced with random shock and selective shock. The study found that the risk of contagion effects caused by the shock was largest in the banking system with small-world network, and it was the smallest under the scale-free network, which was not related to bank's homogeneity or heterogeneity. In addition, Bao and Sun [14] showed that the center-edge hierarchical network would increase the scope and degree of financial contagion risk compared to fully connected network.

The above theoretical research shows that the completely structured banking network system is more stable than the incomplete structure under the simple network. However, considering the complexity of the banking network, it cannot be simply divided into complete and incomplete structures to study its stability. Moreover, it is found that the stability of the banking system under different network structures varies with the network parameters, the heterogeneity and homogeneity of banking system and the impact it faced. Furthermore, the research has shown that the banking system presents a "robust and fragile" characteristic.

\section{Empirical Research}

The empirical research on the banking system stability under different network structures is mainly divided into two aspects: firstly, it usually uses the actual data to analyze the banking system (financial system) in different countries, and explore the characteristics of the network it presents; secondly, it empirically studies the stability of the banking system under different network structures.

Most scholars conduct empirical research on the characteristics of their na- 
tional banking network systems by collecting the relevant actual data. Some scholars including Boss et al. [15], Becher et al. [16], Martinez-Jaramillo et al. [17] and Gabrieli [18] studied the banking network system in Austria, UK, Mexico and Europe respectively, which all showed their banking system had the characteristics of small-world network. Among them, Boss et al. [15] was one of the earliest empirical researchers who specifically studied the bank's network topology. Gabrieli [18] found that European overnight interbank network was very sparse. In addition, Liu et al. [19] used China's interbank lending market relevant data during the financial crisis of 2007-2009 to construct a corresponding interbank lending network. The results showed that the interbank lending market in China had typical small-world and scale-free network features.

Different from the above studies, Inaoka et al. [20], Cont et al. [21], León and Berndsen [22] and Sui and Wang [23] studied the banking or financial network system in Japan, Brazil, Columbia and China respectively, which all showed the banking or financial system had the feature of scale-free network. Among them, Inaoka et al. [20] found that the cumulative distribution of Japanese banking network followed the power law distribution, thus judged its banking network to be a scale-free network with self-similar characteristics. Cont et al. [21] based on the mutual interbank lending and capital data of Brazil financial institutions, found that the degree of connectivity and lending between different financial institutions in Brazil were very heterogeneous, indicating that the Brazil financial system could be portrayed with scale-free weighted network (thick tail and weighted distribution). León and Berndsen [22] found that the Colombian financial network exhibited a modular scale-free structure, which had the following advantages: 1) the power-law distribution due to heterogeneity made the financial network robust against random shocks, but it was vulnerable to targeted shocks; 2) modular scale-free structure tend to make the financial network robust and flexible, but also vulnerable. Sui and Wang [23] used bank's balance sheet data during 2007-2010 in China to analyze the characteristics of its interbank network. The study found that the interbank network showed scale-free network characteristics. Moreover, the interbank network parameters in China were the smallest and the network concentration was the highest compared with other countries. Also, Ba et al. [24] pointed out that most of the current studies have shown that financial networks have the characteristics of both small-world and scale-free networks, and these characteristics significantly affect the contagion of crisis.

In addition, Iori et al. [25] and Bargigli et al. [26] both empirically studied the network structure of interbank market in Italy, but obtained different conclusions. Iori et al. [25] found the Italian interbank market to be a random network while, Bargigli et al. [26] found it as hierarchical network structure and may have different structural features at different layers. Furthermore, if the entire interbank market network consider one kind of structure or represented by the structure of one of the layers, it may not effectively depict the structure of the interbank lending network and thus erroneously assess the systemic risks and 
stability. Veld and Lelyveld [27] used the 1998-2008 Dutch interbank lending market dataset to do the Monte Carlo simulation and calculate the error score of the connection number of different network models, then compared the random network model and the deterministic network model (the network structure was assumed, such as nested split diagram, core-edge network). The research found that the core-edge network model was more suitable for empirical than random graphs, priority connected network and nested split maps. Moreover, there were indeed systemically important core banks in Dutch interbank market, and the core banks had a greater impact on the overall banking system. Furthermore, the research showed that although core banks were indeed related to the size of total assets, there were still some medium-sized banks and other insignificant banks such as small ones found in the core banks.

A few scholars empirically studied on the stability of banking system under different network structures, mainly Degryse and Nguyen [28], Gao and Pan [29]. Degryse and Nguyen [28] based on the actual data from Belgian interbank market, and found that when the structure of interbank market evolved from a fully-regular network to a network with multiple monetary centers, the scope of bank's risk contagion would be smaller and smaller. Therefore, the influence of the interbank market structure on the way of contagion risk was very important. Gao and Pan [29] used the actual data of 61 banks in China in 2009 to explore the contagion effect in the banking system based on the perspective of interbank credit risk and liquidity risk. By controlling the probability distribution of interbank lending, they deeply analyzed the impact of different interbank market structures on contagion effect. The study found that compared with the fully decentralized market structure, the default banks and core capital losses caused by a single bank default both increased significantly under the relatively centralized structure.

The above empirical research shows that the banking or financial network system in most countries has the characteristics of small-world or scale-free network. In addition, there are indeed systemically important core banks in the banking system, and the core banks have an important influence on the stability of banking system. Furthermore, the comparative study empirically has shown that the different network structures of the banking system would lead to different analysis results of financial stability. According to the above-mentioned empirical analysis of the network structure of banking system in different countries, we summarize the results in Table 2. It can be seen from Table 2 that the network structure of each country's banking system presents different characteristics, most of which are scale-free network or small-world network.

\section{Conclusion}

This paper has reviewed the stability of banking system under different network structures. According to our review, it can be seen that scholars mainly use the complex network theory to study the stability of the banking system based on 
Table 2. The characteristics of network structure of each country's banking system.

\begin{tabular}{|c|c|c|}
\hline Researcher & Country & Network characteristics of the banking system \\
\hline Boss et al. (2004) & Austria & $\begin{array}{l}\text { Had group structure and hierarchical } \\
\text { structure features, also exhibited typical } \\
\text { small-world structure characteristics. }\end{array}$ \\
\hline Inaoka et al. (2004) & Japan & Scale-free network with self-similar features \\
\hline Iori et al. (2008) & Italy & Random network \\
\hline Becher et al. (2008) & UK & Small-world network \\
\hline Cont et al. (2010) & Brazil & Scale-free weighted network \\
\hline Martinez-Jaramillo et al. (2010) & Mexico & Small-world network \\
\hline Gabrieli (2011) & Europe & $\begin{array}{l}\text { Had a small-world network feature } \\
\text { and its network was very sparse }\end{array}$ \\
\hline Veld and Lelyveld (2014) & Netherlands & There were systemically important core banks \\
\hline León and Berndsen (2014) & Colombia & Modular scale-free structure \\
\hline Liu et al. (2014) & China & $\begin{array}{l}\text { With typical small-world and } \\
\text { scale-free network features }\end{array}$ \\
\hline Sui and Wang (2015) & China & Exhibited scale-free network features \\
\hline Bargigli et al. (2015) & Italy & Had a hierarchical structure \\
\hline
\end{tabular}

Source: papers download from Web of Knowledge and CKNI.

the network structure. The theoretical research shows that a simple banking network structure cannot effectively reveal the internal relationship between the network structure of the banking system and its stability, and the empirical research has confirmed that most of the banking networks in reality are represented by scale-free or small-world network. Therefore, the future theoretical studies shall focus on the stability of the banking system under complex network structures, and deeply discuss the impact of different network parameters. The existing empirical studies on the characteristics of the banking network of various countries have provided rich results, however, the comparative studies on the stability of banking system under different network structures have been relatively few, which also needs other scholars to continue to explore.

\section{Acknowledgements}

We acknowledge the support from the National Natural Science Foundation of China under Grant No. 71371046, and the Fundamental Research Funds for the Central Universities.

\section{References}

[1] Allen, F. and Gale, D. (2000) Financial Contagion. Journal of Political Economy, 108, 1-33. https://doi.org/10.1086/262109

[2] Freixas, X., Parigi, B.M. and Rochet, J.C. (2000) Systemic Risk, Interbank Relations, and Liquidity Provision by the Central Bank. Journal of Money, Credit and Banking, 32, 611-638. https://doi.org/10.2307/2601198 
[3] Babus, A. (2005) Contagion Risk in Financial Networks. Erasmus Universiteit Rotterdam/Tinbergen Institute.

[4] Thurner, S., Hanel, R. and Pichler, S. (2003) Risk Trading, Network Topology and Banking Regulation. Quantitative Finance, 3, 306-319.

https://doi.org/10.1088/1469-7688/3/4/307

[5] Elsinger, H., Lehar, A. and Summer, M. (2006) Risk Assessment for Banking Systems. Management Science, 52, 1301-1314. https://doi.org/10.1287/mnsc.1060.0531

[6] Acemoglu, D., Ozdaglar, A. and Tahbaz-Salehi, A. (2015) Systemic Risk and Stability in Financial Network. American Economic Review, 105, 564-608.

https://doi.org/10.1257/aer.20130456

[7] Krause, A. and Giansante, S. (2012) Interbank Lending and the Spread of Bank Failures: A Network Model of Systemic Risk. Journal of Economic Behavior and Organization, 83, 583-608. https://doi.org/10.1016/j.jebo.2012.05.015

[8] Teteryatnikova, M. (2014) Systemic Risk in Banking Networks: Advantages of “Tiered” Banking Systems. Journal of Economic Dynamics \& Control, 47, 186-210. https://doi.org/10.1016/j.jedc.2014.08.007

[9] Sui, C., Chi, G.T. and Wang, Z.R. (2014) Network Structure and Systemic Risk by Banks. Journal of Management Sciences in China, 17, 57-70. (In Chinese)

[10] Borgatti, S.P. and Everett, M.G. (2000) Models of Core/Periphery Structures. Social Networks, 21, 375-395. https://doi.org/10.1016/S0378-8733(99)00019-2

[11] Lux, T. (2015) Emergence of a Core-Periphery Structure in a Simple Dynamic Model of the Interbank Market. Journal of Economic Dynamics \& Control, 52, A11-A23. https://doi.org/10.1016/j.jedc.2014.09.038

[12] Lenzu, S. and Tedeschi, G. (2012) Systemic Risk on Different Interbank Network Topologies. Physica A, 391, 4331-4341. https://doi.org/10.1016/j.physa.2012.03.035

[13] Li, S.W. and He, J.M. (2012) Investigating Interbank Contagion Risks under Different Network Structures. Journal of Industrial Engineering and Engineering Management, 26, 71-77. (In Chinese)

[14] Bao, Q. and Sun, Y.X. (2014) Financial Structure and Financial Contagion from the Network Perspective. Systems Engineering-Theory \& Practice, 34, 2202-2211. (In Chinese)

[15] Boss, M., Elsinger, H. and Summer, M. (2004) The Network Topology of the Interbank Market. Quantitative Finance, 4, 677-684. https://doi.org/10.1080/14697680400020325

[16] Becher, C., Millard, S. and Soramki, K. (2008) The Network Topology of CHAPS Sterling, Bank of England. Bank of England, London, 355.

[17] Martinez-Jaramillo, S., Perez, O.P., Embriz, F.A. and Dey, F.L.G. (2010) Systemic Risk, Financial Contagion and Financial Fragility. Journal of Economic Dynamics and Control, 34, 2358-2374. https://doi.org/10.1016/j.jedc.2010.06.004

[18] Gabrieli, S. (2011) The Microstructure of the Money Market before and after the Financial Crisis: A Network Perspective. Research Paper 181.

[19] Liu, C., Wu, M.W. and Ma, Y.J. (2014) A Study on Features of Interbank Market Based on Complex Network Theory-For Data Around Financial Crisis (2007-2009). The Theory and Practice of Finance and Economics, 35, 9-15. (In Chinese)

[20] Inaoka, H., Takayasu, H., Shimizu, T., Ninomiya, T. and Taniguchi, K. (2004) Self-Similarity of Banking Network. Physica A: Statistical Mechanics and Its Applications, 339, 621-634. https://doi.org/10.1016/j.physa.2004.03.011 
[21] Cont, R., Moussa, A. and Santos, E. (2010) Network Structure and Systemic Risk in Banking Systems. Social Science Electronic Publishing, Rochester.

[22] León, C. and Berndsen, R. (2014) Rethinking Financial Stability: Challenges Arising from Financial Networks' Modular Scale-Free Architecture. Journal of Financial Stability, 15, 241-256. https://doi.org/10.1016/j.jfs.2014.10.006

[23] Sui, C. and Wang, Z.R. (2015) Interbank Network Scale-Free Characteristics. Journal of Management Sciences in China, 18, 18-26. (In Chinese)

[24] Ba, S.S., Zuo, W. and Zhu, Y.Q. (2013) The Influence of Financial Networks and Contagion on Financial Stability. Research on Financial and Economic Issues, No. 2, 3-11. (In Chinese)

[25] Iori, G., Masi, G.D., Precup, O.V., Gabbi, G. and Caldarelli, G. (2008) A Network Analysis of the Italian Overnight Money Market. Journal of Economic Dynamics and Control, 32, 259-278. https://doi.org/10.1016/j.jedc.2007.01.032

[26] Bargigli, L., Iasio, G.D., Infante, L., Lillo, F. and Pierobon, F. (2015) The Multiplex Structure of Interbank Networks. Quantitative Finance, 15, 673-691. https://doi.org/10.1080/14697688.2014.968356

[27] Veld, D. and Lelyveld, I. (2014) Finding the Core: Network Structure in Interbank Markets. Journal of Banking \& Finance, 49, 27-40. https://doi.org/10.1016/j.jbankfin.2014.08.006

[28] Degryse, H. and Nguyen, G. (2007) Interbank Exposures: An Empirical Examination of Contagion Risk in the Belgian Banking System. International Journal of Banking Central, 3, 123-171.

[29] Gao, G.H. and Pan, Y.L. (2012) Financial Interlinkages and Contagion Risk in the Interbank Market in China. Journal of Industrial Engineering and Engineering Management, 26, 162-168. (In Chinese) 